\title{
Building Knowledge Infrastructures for Empowerment: A Study of Grassroots Water Monitoring Networks in the Marcellus Shale
}

\author{
Kirk Jalbert \\ FracTracker Alliance/jalbert@fractracker.org \\ Center for Science, Technology and Society, Drexel University, USA
}

\begin{abstract}
This paper characterizes the activities of two nongovernmental environmental monitoring networks working to protect watersheds in the Northeast United States from the impacts of shale oil and gas extraction. The first is a grassroots coalition of advocacy groups. The second is a large network managed by academic institutions. In both cases, knowledge infrastructures were built to distribute resources and to assist members in using data to make scientific claims. I find that the designs of these knowledge infrastructures can reproduce entrenched dynamics of power in ways that advance the agendas of some stakeholders more than others. However, findings also suggest that the 'grassroots' of infrastructures can tactically alter power relationships and redistribute resources to their advantage. By bringing a discourse of power and empowerment into the study of knowledge infrastructures, this paper offers a theoretical contribution to better understand the conditions by which marginalized stakeholders shape knowledge work to deal with complex scientific and environmental problems.
\end{abstract}

Keywords: knowledge infrastructures, public empowerment, citizen science, environmental justice

\section{Introduction}

Across the United States, energy companies are drilling for oil and natural gas using often disputed methods of extraction known as hydraulic fracturing-a drilling technique that injects million of gallons of water and chemical additives into a well to release hydrocarbons from underground shale rock formations. Complicit in this process is the use of horizontal drilling, which allows operators to extend their reach as far as two miles in any direction (US Energy Information Agency, 1993). In addition to tens of thousands of wells that have been "fracked" in the U.S., recover- able shale oil and gas deposits can also be found throughout North and South America, Europe, Africa, Asia, and Australia (US Energy Information Agency, 2013).

A growing body of evidence suggests that, amongst other environmental threats, watersheds in the vicinity of hydraulic fracturing operations can be impacted by numerous extraction-related problems including seepage from damaged gas well casing, improper waste disposal, trucking accidents, and underground migration of drilling fluids (Donlin, 2010; Entrekin et al., 2011; 
Llewellyn et al., 2015). Assessing these impacts is complicated by the fact that hydraulic fracturing is a poorly regulated practice. In the U.S., drilling companies are largely exempt from the Safe Drinking Water Act and the Clean Water Act (Soraghan, 2011). Some states do not require companies to disclose records of chemicals used in drilling; others lack timely systems to notify the public of regulatory violations (Malone et al., 2015).

Due to this lack of transparency, efforts to understand hydraulic fracturing's impacts have largely fallen on the shoulders of the civil society (nongovernmental) sector-academic researchers, non-profit advocacy organizations, citizen scientists, and concerned citizen groups. In the Marcellus Shale, one of the most actively drilled formations in the Northeast U.S., civil society groups have established surface water monitoring programs to assess potential changes in water quality that might result from oil and gas extraction. Beginning in 2010, a number of capacity building organizations (typically nonprofits that provide services to local environmental groups) developed sampling and quality assurance plans to assist concerned citizens in measuring basic water quality indicators (Jalbert et al., 2014; Kinchy \& Perry, 2012). Training programs were organized to propagate standardized protocols and to establish larger monitoring networks. Private foundations provided funds to purchase equipment for these groups, ranging from $\$ 100$ handheld pocket meters to $\$ 1,000$ automated "data logger" devices (Jalbert \& Kinchy, 2015). Meanwhile academic researches grew interested in aggregating rapidly accumulating data for long-term ecological assessments and watershed-wide geospatial mapping projects.

While civil society water monitoring programs have been active in the region since the early 1970s, this groundswell of new monitoring efforts that emerged in response to shale oil and gas development is significant. In only five years, this field matured from a dispersed collection of projects into a vast community of stakeholders accumulating social capital and technical resources to collect data and ask meaningful questions. The people who invested in these efforts believed that, by generating their own science, they would be empowered to participate in public debates and influence regulatory decision-making.

\section{Knowledge Infrastructures for Civil Society Science}

In the science and technology studies (STS) literature, scholars have argued that civil society science groups can alter the balance of power between at-risk communities, regulatory agencies, and polluting industries by developing the means to generate independent knowledge (Corburn, 2005; O'Rourke \& Macey, 2003; Ottinger, 2009; Overdevest \& Mayer, 2008). This research also illustrates how grassroots monitoring groups can overcome barriers of scientific legitimacy by forming partnerships with experts in professional organizations and academic institutions (Lave, 2012; Morello-Frosch et al., 2005; Savan et al., 2003; Wagenet \& Pfeffer, 2007). Such partnerships can coalesce resources, improve data collection methods, open doors to laboratories, and enlist specialists who assist groups in solving technical issues. In this paper, I argue that civil society groups in the Marcellus Shale, when assembling resources and building broader alliances for water monitoring research, also constructed distinct "knowledge infrastructures" (KIs) to question scientific assessments often dominated by powerful institutions.

Foundational research in STS on infrastructures focused on the construction of large-scale development projects, such as electrical grids and transportation projects (Bijker et al., 1987; Hughes, 1987), as well as on computing systems that support cooperative work environments (Bowker et al., 2010; Edwards et al., 2009; Star \& Ruhleder, 1996). Recent scholarship has sought to identify and understand the mechanisms of knowledge production, where the "internetworks of people, artifacts, and institutions which generate, share, and maintain specific knowledge about the human and natural worlds" come together (Edwards et al., 2013: 23). While important aspects of water monitoring infrastructures include the wide array of monitoring protocols, data collection tools, and data management systems in use-topics dealt with extensively in prior publications (Gouveia et al., 2004; Pfeffer \& Wagenet, 
2007; Jalbert et al., 2014; Jalbert \& Kinchy, 2015)— the emphasis of this paper is on the social side of knowledge infrastructures; on the relations of people and organizations that define research partnerships.

One of the core concepts in $\mathrm{KI}$ research explored in this paper suggests that infrastructures stabilize and become rigid in their maturity. Converging designs can push out other competing standards, instrumentations, and organizational structures, thus fusing how an infrastructure's stakeholders share resources and political power (Pinch \& Bijker, 1987; Star \& Ruhleder, 1996). Edwards et al. (2013: 13) note that, when this occurs in Kls, it can have "significant distributional consequences, advancing the interests of some and actively damaging the prospects of others." The KI literature has investigated how these struggles occur when defining the meanings of knowledge and data used by stakeholders (Borgman et al., 2012; Bowker \& Star, 1999; Edwards et al., 2011). Others have looked at how an infrastructure's intended functions can "break down" and reveal inner tensions (Ribes \& Finholt, 2009; Star, 1999).

These are important developments in figuring out the nature of knowledge work, but there remains a gap in understanding relationships of power and empowerment in these struggles. I argue in this paper that Kls can remain amazingly dynamic spaces where power is continually negotiated. An infrastructure's stability can become susceptible to competing demands when the marginalized, peripheral, or what I refer to here as the "grassroots," of infrastructures forward objectives that differ from those who are perceived to have control over infrastructural development. Tactical resistance seeks to change how an infrastructure works while also keeping the core of the infrastructure functionally intact. In the case of research infrastructures built to make sense of environmental pollution, acts of resistance are, at their core, also struggles to build capacity for dealing with real life injustices.

\section{Assessing Power and Empowerment in Knowledge Infrastructures}

Bowker et al. (2010: 106) have argued "if participants have been active in the formation of infrastructure elements, they are more likely to have a deeper awareness of alternatives and have had a voice in mediating choices inherent to issues such as standards formation and community goals." The nature of participation and what it means to have voice in infrastructure building is, however, not well understood. STS researchers have developed a robust language to describe new forms of participatory research including citizen science, community-based science, street science, and crowdsourcing science (Corburn, 2005; Fischer, 2000; Irwin, 2001; Moore, 2006). Each of these seeks to illustrate the ways in which professionals and nonprofessionals negotiate power at different stages of research.

One of the more prominent models to emerge comes from the natural sciences and is offered by Shirk et al. (2012). At one end of their spectrum of participation are "contributory" projects, where volunteers collect data for scientists but otherwise have little control over the nature of research. On the other end are "co-created" projects, designed in equal partnerships, that emphasize shared decision-making. Models for evaluating participation are relatively absent from $\mathrm{KI}$ studies, but could clarify how KIs engender certain liabilities for less powerful grassroots groups, particularly when they must relinquish control over their work in order to participate in larger research programs.

Similar to poorly defined metrics of participation in infrastructure building, assessments of empowerment-the increased capacity of an infrastructure's stakeholders to design, implement, and evaluate mechanisms that improve their standings in the world-is also weakly defined. Here, I look to the contributions of critical geography, which has a long history of appraising empowerment in knowledge construction projects, particularly in the use of geographic information systems (GIS). For instance, Corbett and Keller (2005a, 2005b) make a distinction between empowerment-"a tangible increase in social influence or political power"-and empowerment capacity-"aspects of the deeper process of change in the internal condition of an individual or community that influence their empowerment" (Corbett \& Keller, 2005b: 28). They suggest that catalysts for empowerment can come from gaining access to new information, learning new technical skills, or developing fresh political strat- 
egies. Their framework makes a further distinction in that empowerment and empowerment capacity can evolve differently at the scale of the individual versus that of the larger community.

In the remainder of this paper I familiarize assessments of participation and empowerment with $\mathrm{KI}$ studies through an examination of two civil society water monitoring networks operating in the Marcellus Shale. The first, built by a coalition of concerned citizen groups called the New York Water Sentinels, was formed in 2011 and later expanded through loose affiliations with the Sierra Club (one of the largest and oldest environmental advocacy organizations in the United States). With an annual budget of only $\$ 20,000$, roughly 150 volunteers now monitor streams in twelve counties across New York State. The second monitoring network emerged from a project called Three Rivers QUEST (3RQ). 3RQ is supported by $\$ 1.3$ million in grants awarded to West Virginia University's Water Research Institute by a nonprofit foundation. 3RQ supports a variety of water monitoring programs across the states of Pennsylvania, West Virginia, Maryland, and Ohio.

I find that the Kls built by these two research communities are similar in terms of the resources they offer to their affiliated stakeholders. They differ in the extent to which grassroots members retain control over research agendas at various points of KI development. Relationships of power are found to heavily depend on adopted models of participation that can either aggregate or distribute power, authority, and expertise. I also show that Kls can elude stability and change over time when marginalized groups develop tactics to influence the direction of scientific research. These findings bring to the forefront the importance of evaluating the attributes of participation and empowerment when assessing the long-term affordances of Kls.

\section{Data Sources and Research Methods}

Data supporting this paper was gathered from 2011 to 2015 and draws from more than 30 semistructured interviews conducted with a wide range of stakeholders including representatives of water monitoring networks, government agencies, capacity building organizations, nonprofit watershed groups, academic institutions, data management projects, and major funding foundations. The organizations in this paper are identified accurately, however pseudonyms are used in place of people's real names in order to protect personal privacy. All interviewees were granted the right to review their quotations for clarity and context prior to publishing.

Additional data came from more than 1,000 hours of participant observation with groups mentioned in this paper and many others. A great deal of time was spent on the ground with concerned citizens as they trained to participate in water monitoring projects, collected samples in the streams, and analyzed their data. When studying capacity building organizations, participant observation occurred during visits to their offices, by attending strategy sessions, and by being present at regional summits where outreach coordinators interacted with their constituents.

A significant amount of information was also acquired through embedded or "engaged" research activities that emerged organically when interlocutors asked for assistance with their efforts. As an appointed member of the New York Water Sentinels' science advisory committee, I was able to join weekly planning calls and offer insights from the research. Other discernments came from coordinating quarterly meetings of the "Water Quality Data Coordinator Group" in 2014 and 2015. These gatherings brought together more than twenty representatives from across the Marcellus Shale water monitoring community to build data sharing synergies. Finally, insights offered in this paper came from my experiences as a visiting researcher from 2012 to 2015 with the FracTracker Alliance-a Pennsylvania-based nonprofit that works to enhance public understanding of oil and gas extraction through interactive maps, data analysis, and articles-where I am now the Manager of Community Based Research and Engagement.

\section{Dilemmas of Democratic Governance: The New York Water Sentinels}

"You can see it's kind of gurgling," the person next to me commented as we peered over the edge of an access hatch to a nearly 40 -foot tall 
vat of stewing sludge. The smell was overwhelming and we felt a bit uneasy about the rope and emergency flotation device hanging beside us on the railing. This particular tower was but one in a complex arrangement of pipes, pumps and tanks that processed the regular flow of leachate (liquid waste outflows) from the nearby Steuben County Landfill in the Village of Bath, located in upstate New York (Figure 1). A dozen people stood below us on the next platform, listening intently as the plant manager described how drainage from the landfill entered the system on one end, gets piped through the Village of Bath's sewage system, and is eventually discharged into the Cohocton River, a tributary of the upper Susquehanna River watershed.

The Steuben County landfill is the site of a decades-old township dump, originally constructed without a proper leachate treatment system. In 1995, when the landfill sought expansions, the New York Department of Environmental Conservation (NYDEC) assisted Steuben County in building a treatment plant that would not only have the capacity to process leachate from this landfill, but also wastewater from other sources in the state (Hardman, 2014). One growing market for waste processing came from Pennsylvania's Marcellus Shale oil and gas drilling industry.

Despite New York State's 2008 drilling moratorium, and the more permanent ban on hydraulic fracturing enacted in June 2015, a recent report calculated that more than 460,000 tons of solid waste and 23,000 barrels of liquid waste from shale drilling operations in Pennsylvania were processed in New York (Moran, 2015). Facilities accepting this waste included the Chemung County Landfill, Casella Waste Systems, Seneca Meadows Landfill, Allied Waste Systems, Hyland Facility Association, and the Hakes Landfills. Among these facilities, the Chemung County Landfill has accepted the most solid waste, at nearly 200,000 tons. Hyland Landfill and Hakes Landfills have each accepted over 100,000 tons of drill cuttings. These amounts do not include the tens of thousands of tons of drill cuttings used as "daily cover"-a layer of compressed soil placed on top of a landfill at the end of each day.

Drill cutting are highly valued by landfill operators. Their density takes about one-fourth the space of conventional waste, but can be charged at the same per-ton disposal fee. This new revenue stream persuaded operators to expand

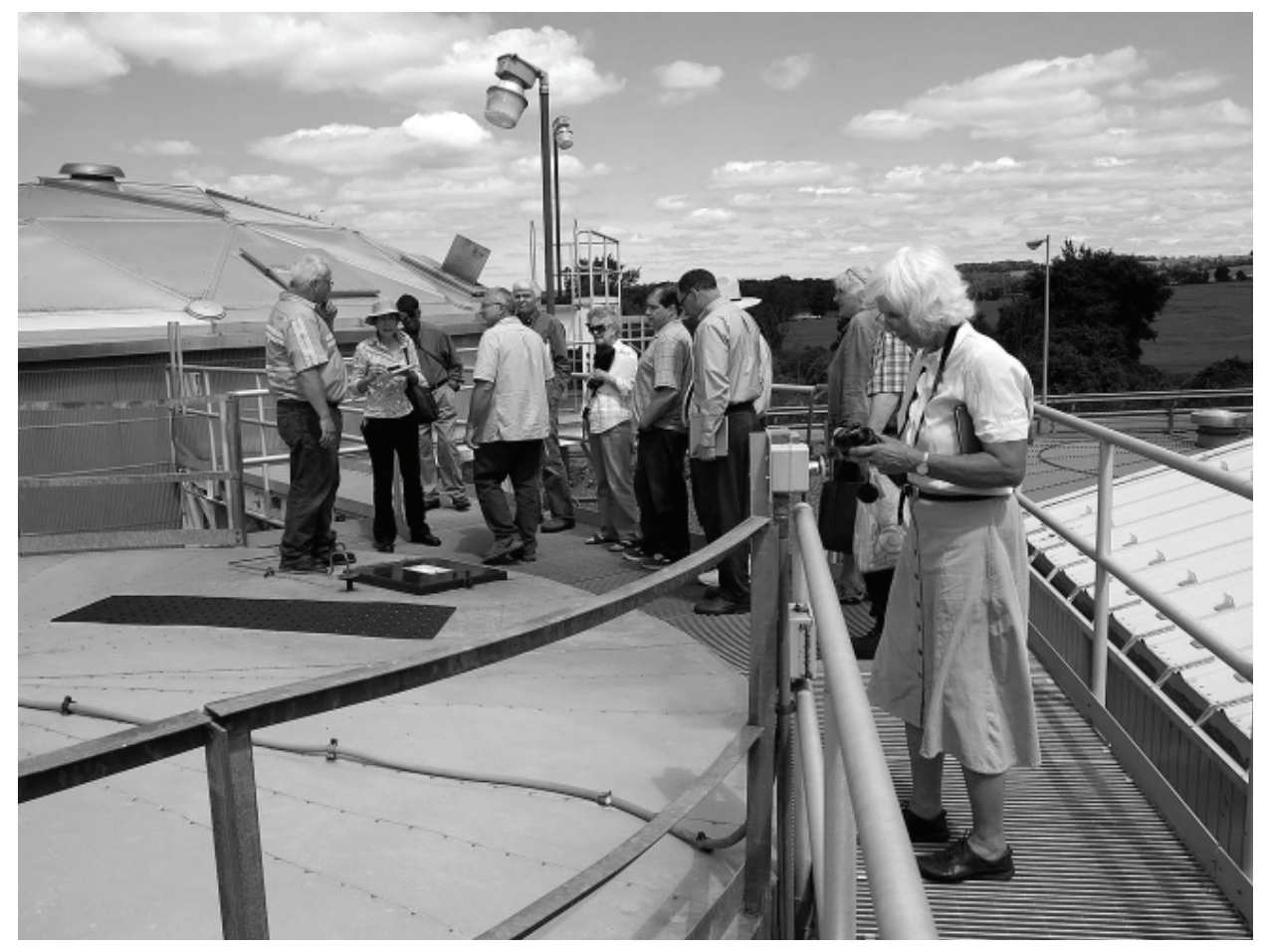

Figure 1. A tour the Steuben County leachate pretreatment plant 
their facilities in tandem with Pennsylvania's expanding shale oil and gas industry. In one case, Chemung County landfill received approval from the NYDEC to expand their volume of accepted waste from 120,000 tons to 180,000 tons per year, and then began diverting less-valuable county waste to other landfills (Mantius, 2013).

A number of loopholes allow shale oil and gas waste to travel into New York even though much of the gas industry's practices are otherwise limited. According to NYDEC regulations, drilling muds are not considered hazardous waste (NYS Department of Environmental Conservation, 2006). Drilling waste is also exempt from New York's Low Level Radioactive Waste Laws that govern Naturally Occurring Radioactive Materials (NORMs) such as uranium, radium 226, and radium 228. Many residents feel this rule fails to acknowledge that Marcellus Shale drill cuttings are known to contain low levels of radioactive materials (Puko, 2013).

The Steuben County landfill, the site of our tour, did not directly accept drilling waste of any kind from the Marcellus Shale, but one fact was known about the facility-its overbuilt wastewater treatment plant generated revenue for the county by accepting excess leachate from neighboring landfills, including more than 2.2 million gallons worth from Hyland landfill, and nearly 2 million gallons from Hakes Landfill between July 2012 and April 2013 (Mantius, 2013). These facts had many residents in the county worried about the safety of public drinking water supplies and nearby watersheds.

\section{Building Grassroots Infrastructures}

Our tour of the Steuben County landfill treatment plant was organized by a local chapter of the New York (NY) Water Sentinels-a grassroots coalition of environmental advocacy groups that began baseline monitoring in watersheds along New York State's border with Pennsylvania in 2011 where Marcellus Shale drilling was expected to occur if the state's moratorium were lifted. The origins of NY Water Sentinels can be traced back to the Concerned Citizens for Cattaraugus County (CCCC), an organization that has worked for years on issues ranging from stopping large windmill farms near homes to opposing new landfills. As part of their initiative to address shale oil and gas issues in New York, the regional Atlantic Chapter of the Sierra Club (representing Northeastern U.S.) became interested in supporting a water monitoring program. The Sierra Club approached the CCCC and provided a seed grant through its National Water Sentinels program to assist members in acquiring equipment. Together they scheduled training sessions with the Alliance for Aquatic Resource Monitoring (ALLARM), an outreach program of Dickinson College in Carlisle, Pennsylvania, that was instrumental in developing volunteer-based shale oil and gas water monitoring protocols across the Marcellus Shale starting in 2010.

Over the next two years the NY Water Sentinels brought on additional volunteers by canvassing at town meetings and local newspapers, as well as by partnering with other regional environmental organizations. Their monitoring network now extends into the watersheds of thirteen counties along the New York and Pennsylvania border where 160 volunteers have made more than 1,500 visits to document conditions at 125 stream sites. I asked Miles Coolidge, an advisor from the Sierra Club Atlantic Chapter who sits on the Steering Committee, about how the NY Water Sentinels evolved. In succinct terms, he described the birth of a grassroots knowledge infrastructure:

\footnotetext{
The first year we spent a lot of time getting the QA/ QC to work. We built the technical infrastructure. The second year we worked on getting the coordinator groups working - the social infrastructure. Now we need to do more outreach into challenging areas, to develop that sense of community. Our value is to work at the local level. We have to make sure we are embedded in the community.
}

The NY Water Sentinels have no paid staff or dedicated facilities. Its governing system is one of overlapping committees populated by volunteers. The Steering Committee is the executive body, and is responsible for managing the infrastructure's broader mission. This includes establishing new affiliations with outside partners, determining where future training will occur, making changes to monitoring protocols and how data will be used, as well as deciding what political or 
legal initiatives they may initiate. Steering Committee members are elected annually by Water Sentinels chapters, but also consist of members of the Sierra Club Atlantic Chapter office who serve an advisory role. Day-to-day governance of the NY Water Sentinels falls upon the Coordinators Committee. Its purpose is to implement the directives of the Steering Committee and, in the process, maximize inclusion of the network's volunteers by soliciting input on monitoring strategies. The Coordinators Committee meets weekly by phone to discuss topics ranging from equipment maintenance, data management issues, quality assurance updates, and the status of their finances.

Other working groups that meet on a semiregular basis include an External Communications Committee, a Finance Committee, a Fundraising Committee, and a Data Management Committee-all populated by volunteers in the network. The NY Water Sentinels also retain the help of many outside experts who assist the Steering Committee and Coordinator Committee with different tasks. No less than three practicing attorneys advise the Legal Committee. The
Science Committee (on which this author sits) regularly consults with professors of biological science, geology, and environmental studies at different universities.

\section{The Tradeoffs of Empowerment}

The NY Water Sentinels created what Shirk et al. (2012) might call a "co-created" partnership structure, one that empowered individuals on the front lines to influence the design of their KI. However, these same egalitarian systems also made the network vulnerable to internal friction and competition for resources. The story of how this unfolded within the NY Water Sentinels began at the Hyland Landfill in Wellsville, New York.

In 2013 Casella Waste Systems applied for a permit to expand Hyland Landfill's annual volume of accepted waste by more than $60 \%$ in order to accommodate Pennsylvania's drilling cuttings (Donohue, 2015). When this became public knowledge, two members of the local NY Water Sentinels chapter felt it was important to begin monitoring around the landfill as well as its wastewater treatment plant. "We didn't find

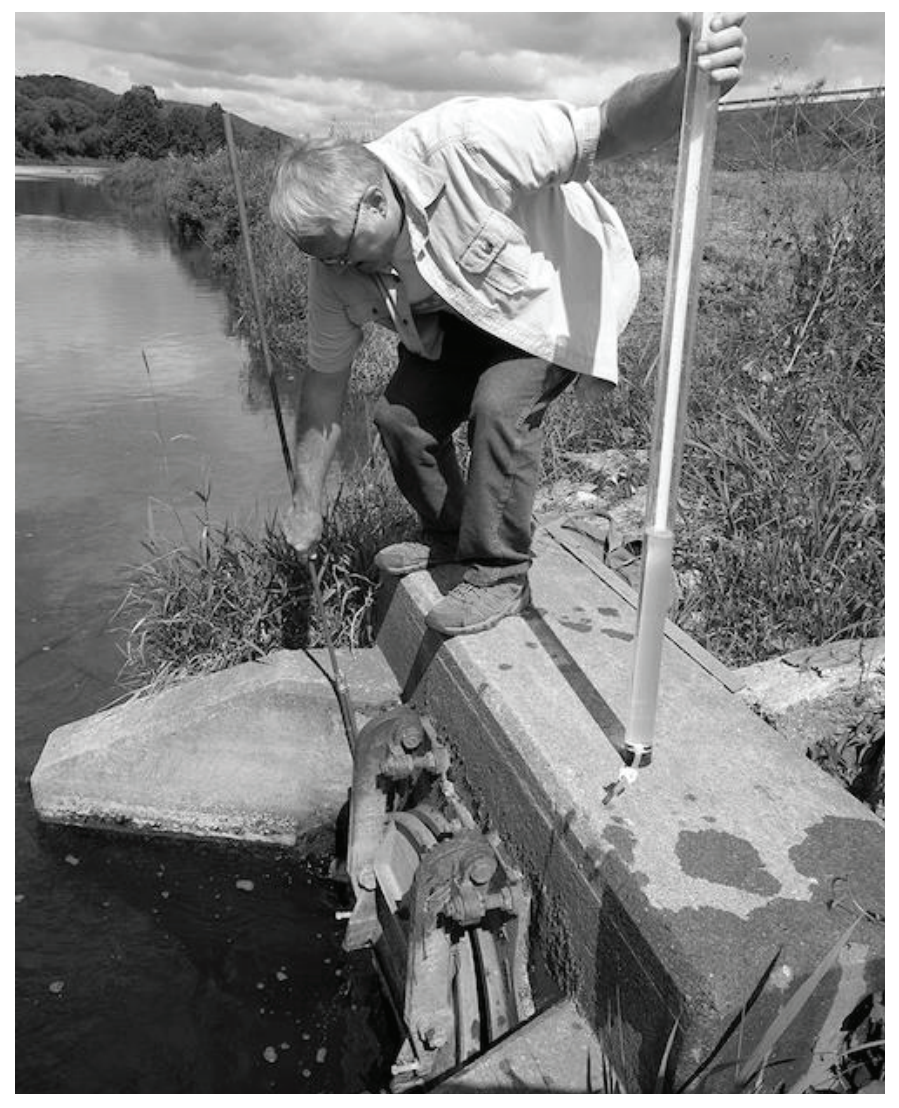

Figure 2. Water sampling at a leachate treatment plant outflow pipe 
any elevated radioactivity from the Wellsville Water Treatment plant discharge, but we did find elevated radioactivity in a stream running off from the landfill at a designated outfall," Gavin Erwitt, the chapter's coordinator, explained.

As word spread about the possible radioactive risks of drilling waste entering the state, other NY Water Sentinels volunteers began monitoring the outflows of landfills and wastewater treatment plants in their region (Figure 2). Increased attention to landfills quickly became a contentious issue. Some members felt that chasing landfills compromised carefully laid plans for conducting watershed-wide baseline studies. Other concerns were raised as to whether or not taking an advocacy-oriented position would undermine the NY Water Sentinels' ability to raise funds from scienceminded benefactors. By contrast, proponents of landfill monitoring were quick to point out that the industry may apply enough pressure to reverse the recent ban on high-volume hydraulic fracturing if natural gas prices rebounded from current record lows. In their view, the ban created an opportunity to extend their mission and take action against other sources of known pollution.

A heated discussion in a Leadership Committee meeting highlighted the character of this debate. "The assumption of our original mission was that fracking would eventually come to New York and we needed to prepare for it," a committee member commented.

A second committee member had a different perspective. "We did originally say that we needed the data to understand baseline. But we need to have the conversation that, now that we have data and we know more, should we expand our mission?" They continued, "Getting people involved at the community level in water quality is an important facet of making a difference. We always incorporated that as part of our discourse. But we haven't been as active in that area as we could be. So the efforts around the Hyland landfill illustrate to me how important outreach is to these areas."

"Well, we should also have a discussion of how this changes the political posture of our groups," a third committee member responded, "Our group has a history of 'opposing' things. Baseline monitoring allowed us to get involved in something that was more objective and positive, to just look at possible violations. Landfill monitoring would bring us back to being a bad-boy watchdog. This is a conversation each group will have to have."

These debates would continue in following months while most NY Water Sentinels chapters continued their usual baseline monitoring work. Nevertheless, volunteers that did take up the cause of landfill monitoring would eventually influence allocations of resources in their infrastructure and draw in outside allies. A dedicated protocol for landfill monitoring was developed with the help of staff at ALLARM, volunteers used funds to purchase equipment for collecting samples around treatment plants, and a nearby laboratory offered to process these samples at cost.

These subtle shifts in resource allocations show some of the benefits of KIs that emerge from partnerships with equal power sharing. When the NY Water Sentinels program began, it emphasized the importance of doing science at the local level. Its resulting governing system respected input from its individual members when steering their KI's development. Some monitoring groups expanded their capacity for empowerment by having the freedom to address new problems discovered in the course of water monitoring. However, for a KI with limited resources, increasing the empowerment capacity of some came at a cost to others with different ideas about how to influence environmental debates. The story of landfill monitoring reveals how KIs can be fluid things and internal power can shift due to the levers of democratic governing systems.

\section{Institutionalizing Grassroots Infrastructures}

KIs can also change in moments of vulnerability, such as when resources become scarce, or when citizen scientists struggles for legitimacy. Stakeholders may appeal to powerful institutions for financial, political, or technical support. In these instances, KIs can become susceptible if strengthening alliances with institutions also means giving up control in deciding how KIs function.

By the summer of 2014, the NY Water Sentinels had grown into a formidable presence in New York State. Member groups planned to monitor 
as many as 150 sites and would offer two new training programs, which they estimated would attract 30 new volunteers. These and other programming expenses, such as public outreach events and laboratory analysis, would be covered by a 2015 budget of roughly $\$ 22,000$. Unfortunately, the Sierra Club eliminated funding for the National Water Sentinels program at the end of the 2014 fiscal year-a fund that underwrote more than $60 \%$ of the NY Water Sentinels' annual budget.

Loss of a major funding source meant that the NY Water Sentinels had to find a way to sustain their hard-won research program by other means. One possibility was to maintain the status quo as a semi-autonomous affiliate of the Sierra Club. They had learned in the past, however, that obtaining funding for local projects while under the umbrella of a large environmental nonprofit could be difficult. Another solution was to become a wholly independent nonprofit, leaving behind their long-time Sierra Club benefactors. This idea did not sit well with those who had been members of the Sierra Club long before the NY Water Sentinels came into existence. Sierra Club advisors suggested a third possibility: The NY Water Sentinels could become an official subprogram of the Sierra Club Atlantic Chapter. The Steering Committee weighed their options and, in late 2014, elected to officially affiliate with the Sierra Club Atlantic Chapter.

Being part of the Sierra Club allowed the NY Water Sentinels to apply for new funding, but the decision had other implications as well. Under their new charter, individual monitoring groups would be required to report their activities in Steering Committee meetings as before, but also now had to report to the Sierra Club Atlantic Chapter's Conservation Chair. Groups could make recommendations to undertake a legal action, but were not permitted to act independently without a detailed review by the Sierra Club. Financially, the NY Water Sentinel's assets would be held in a Sierra Club Foundation account. How these changes might affect the day-to-day operations of the NY Water Sentinels largely remains to be seen. When I asked one chapter coordinator how his group felt about these changes, I was told:
Look, we have meat eaters and hunters and we have-most of our people are Republicans. They don't have any sympathy for the Sierra Club. They are not members of the Sierra Club. I joined the Sierra Club just so I could do this. I wasn't a member of the Sierra Club. There is a difference between grassroots environmentalism, which is what we do, and aesthetic environmentalism, which is what the Sierra Club does. Our interest is in protecting our backyards. We are NIMBYs [Not In My Back Yard] and we wear the NIMBY badge with honor. The Sierra Club Atlantic Chapter, of people that are involved here, are paid staff. They seem to have little understanding of what it takes to organize and maintain an entirely volunteer group.

These comments reflect how building closer ties to the Sierra Club made some NY Water Sentinel members uncomfortable with the new arrangement. Individual volunteers who had invested time and resources in building the NY Water Sentinels' KI wanted to have a say in its daily operations and broader objectives. Some groups, like the CCCC, also had a long history working in their communities and understood what it took to bring people together and sustain their membership. These groups resented the notion that the Sierra Club might dictate organizing tactics, or narrow how they utilized water monitoring for scientific, political, legal, or other purposes. At present, the Steering Committee and the Leadership Committee are looking for ways to retain greater autonomy while part of the Sierra Club Atlantic Chapter. For instance, they are working to refine the Sierra Club's 501c3 tax reporting (required by federal law to designate non-profit expenditures) so funders can tailor their donations for use by individual monitoring groups to work on specific projects.

\section{Uneasy Alliances in Rigid Infrastructures: Three Rivers Quest}

In a different region of the Marcellus Shale, watersheds along southwestern Pennsylvania's border with West Virginia traverse some of the densest coal and natural gas mining fields in the United States. In 2009, researchers from the West Virginia Water Research Institute (WVWRI), based at West Virginia University, began to notice that levels of total dissolved solids (TDS) (a measure of water 
salinity) in the region's watersheds were exceeding U.S. Environmental Protection Agency (EPA) secondary drinking water standards, particularly in tributaries of the Monongahela River. WVWRI researchers deduced that excess TDS was likely coming from coal and gas extraction sites, but they knew little about where and when pollution discharges were occurring.

The Monongahela River flows from West Virginia into Pennsylvania, and eventually meets the Allegheny River to form the Ohio River in the city of Pittsburgh. Experts in the region agreed that a coordinated strategy was needed to bring together the many individual monitoring programs in these three large watersheds. In 2011, the Pittsburgh-based Colcom Foundation awarded the WVWRI $\$ 60,000$ to establish what would become known as Mon River QUEST (Quality Useful Environmental Study Teams), a program to aggregate and analyze data from regional watershed protection groups. WVWRI received an additional $\$ 750,000$ from Colcom in 2012 to expand the program into the Allegheny and Ohio River watersheds-Mon River QUEST was renamed Three Rivers QUEST, or 3RQ. 3RQ received a third grant from Colcom for $\$ 500,000$ in 2013 to develop the "QUEST Data Management Tool" for storing, managing, and mapping water quality data (West Virginia University, 2013).

The $\mathrm{KI}$ built by $3 \mathrm{RQ}$ is a complicated arrangement of organizations and institutions with varying resources and objectives. Early on in the project's design, WVWRI identified three research partners to take stewardship over the different watersheds: Wheeling Jesuit University was assigned the Ohio River, Duquesne University to the Lower Monongahela and Lower Allegheny Rivers, and the Iron Furnace Chapter of the Pennsylvania Council of Trout Unlimited (a state-wide network of sport fishing enthusiasts) to the Upper Allegheny River. WVWRI would continue to oversee the Upper Monongahela River. 3RQ's research partners were responsible for collecting bi-weekly water monitoring samples in their respective watersheds. Each research partner also supervised dispersing competitive $\$ 3 \mathrm{k}-\$ 5 \mathrm{k}$ minigrants to independent watershed groups in their territories. Beneficiaries of these grants ranged from small volunteer groups to large watershed associations with dedicated staff. In total, 3RQ would bring together a monitoring network of some 30 groups collecting samples at more than 300 stream sites in four U.S. states.

3RQ's research partners stressed that the diverse research program they had developed would bring resources and expertise to bear on problems important to local watershed groups. " $3 R Q$ provides a unique opportunity for academic scientists to engage in community based participatory research-that is, water quality issues identified by our community partners helps to prioritize our research efforts," a researcher at one of the partner universities commented in 2013 (West Virginia University, 2013). Research partners further argued that community groups would be empowered by co-designing research with scientific experts. In practice, however, research partners dictated how 3RQ's KI functioned. This affected everything from resource allocations to how data was used when making scientific claims and political statements. Meanwhile, minigrantees who came on board with $3 R Q$ expected to have decision-making powers in their participation. Ultimately, disconnects between 3RQ's founding principles and how the project actually functioned would have major implications for the stability of 3RQ's KI.

\section{Erecting Boundaries of Power and Expertise}

3RQ's research partners possessed a great deal of power when dealing with local watershed groups. One expression of this power was revealed in the process of determining which groups would receive $3 R Q$ mini-grants, which became important resources for bolstering underfunded and understaffed programs in the region. Lisa Greenfield, a watershed specialist in West Virginia, recalled why her organization applied for a mini-grant in saying, "We were really driven by the need for staff support, and not by the resources that the program was going to offer beyond that." Lisa's group received funding from $3 \mathrm{RQ}$ and became part of the monitoring network.

Not all watershed groups were as lucky. Mandy White, a watershed specialist in a Pennsylvaniabased organization, recalled having a different experience. Mandy's organization managed a large network of automated data loggers funded by Colcom. She assumed her organization would be supported by $3 \mathrm{RQ}$ : 
Colcom let us know that, because of this relationship that they had with the WVWRI, they wanted our data in 3RQ. But we did not receive a mini-grant. We applied but we didn't get it. We actually never even got a letter telling us that we didn't receive funds, we just saw the announcement and we were not in it. By that time we had funded the project in other ways, so it wasn't a big deal.

While $3 R Q$ 's rejection was not a major loss for Mandy's organization, 3RQ's growing position of authority as a gatekeeper for watershed science in the region set an expectation that groups would want to partner with $3 R Q$, regardless of whether or not they had received a mini-grant. This was a disempowering experience for other groups with a long history of water monitoring. For example, Colcom would eventually request that Mandy's organization contribute their data to 3RQ's database, but their exclusion from 3RQ's official research program meant that they would have a reduced role in determining how $3 R Q$ might use their data.

In other instances, groups applied for 3RQ minigrants for the explicit purpose of leveraging their data. Rita Levitt, the director of a Pennsylvaniabased watershed association noted, "I mean, it is good to have your own database, but at the same time, you know, a central repository where hopefully it will never disappear, that was, for us, the goal." Decisions to partner with $3 R Q$ on terms of data management were echoed by others who joined the KI. Water monitoring groups needed technologies to store rapidly accumulating data, but what they really desired was assistance from 3RQ's watershed scientists that this arrangement implied. Many people like Rita believed that partnering with a respected research institution would bring legitimacy to their data and reveal hidden evidence of pollution they themselves could not see.

Lisa, Mandy, and Rita's data were stored in a database and GIS system called the QUEST Data Management Tool. While this tool can be evaluated as a technical component of 3RQ's Kl, it also has social significance a it's architecture echoed 3RQ's partnership structure-data entering the system was "tiered" to distinguish its source. Within this classification scheme, bi-weekly samples gathered by 3RQ's research partners were assigned to Tier 1. Tier 2 was reserved for data generated by automated data logger stations. Data from grassroots monitoring programs were placed in Tier 3 (Figure 3). Tiered data made sense to 3RQ's development team, particularly when having to work with regulatory agencies. 3RQ's program director noted:

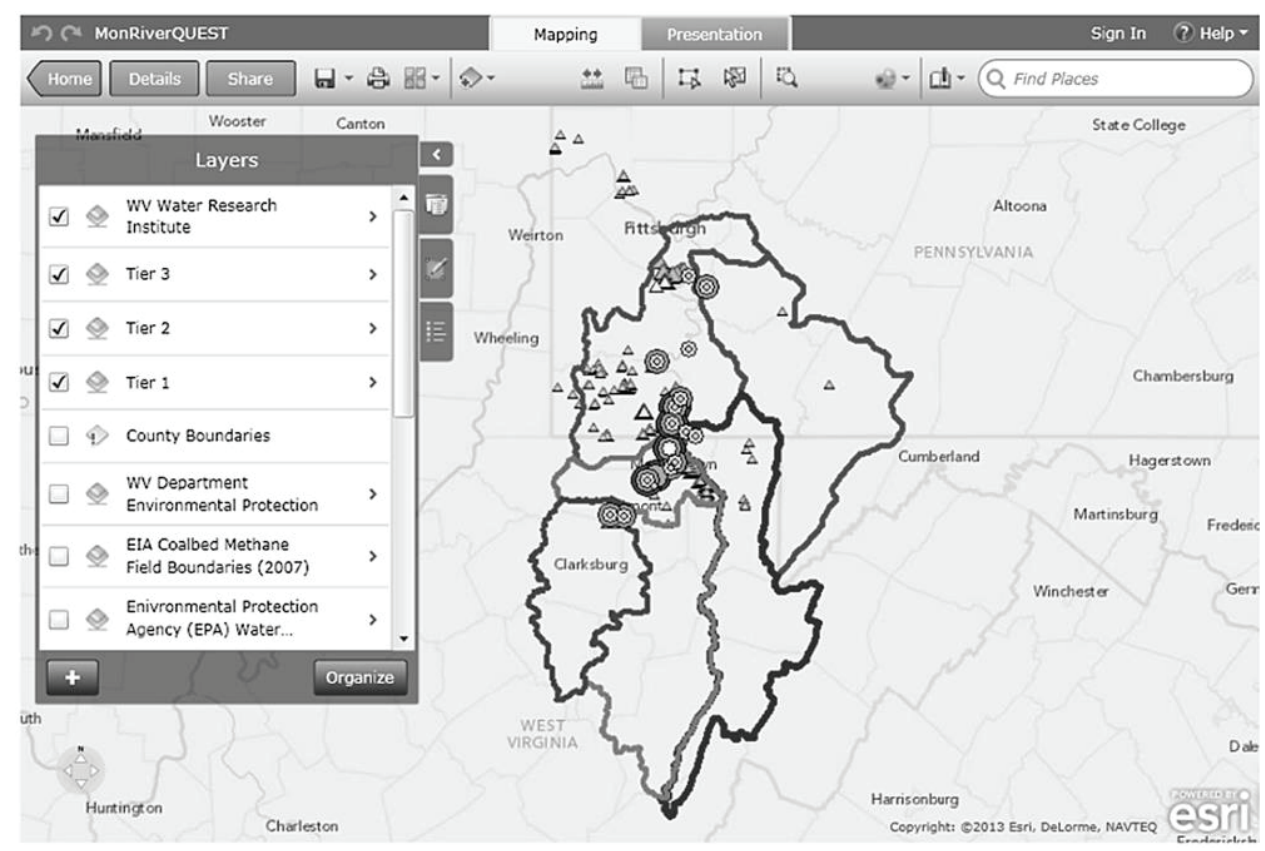

Figure 3. A screen capture of 3RQ's QUEST Data Management Tool (circa 2013)1 
We actually had conversations with the EPA and with the different state agencies, Pennsylvania DEP [Department of Environmental Protection] and West Virginia DEP, early on during the brainstorming phases of bringing on the volunteer component into the program, and that was one of the things that was identified. Whenever they are looking at the data from our website, they wanted to be able to distinguish between what we are collecting and what volunteers are collecting. And then, further, which volunteers are collectinghow much confidence can we give in this data that is being provided.

The tier system was born out of a need to define the characteristics and quality of 3RQ's data. However, representatives from smaller watershed groups I met with argued that 3RQ's data scheme also reflected the KIs overall political landscape. 3RQ's leaders made demands for their data in order to conduct scientific research, but diminished the importance of using data to advocate for impacted communities. These concerns were made plain in my conversation with Lisa Greenfield:

\begin{abstract}
What I don't see QUEST doing at this time, at least not in the way that maybe I would like to see it done, is then turning around, taking this data, and being the leaders - telling our elected officials that this is happening to our rivers and streams and this is what we need to do to protect them. That gets back into the big questions about the Ivory Tower, and who funds your research. I have opinions about the motivations behind some of this research. We might have all this data on our watershed, but how is that helping improve water quality broadly across the state and across the region? Yeah, we hope that nothing bad ever happens, but if it would, it wouldn't be the researchers marching down to Charleston [West Virginia's state capital], it would be us. I don't think they would help us.
\end{abstract}

When a number of watershed groups brought up the issue of 3RQ's reluctant support for advocacy at a regional meeting of mini-grantees, 3RQ's leaders countered that using data for research purposes could produce meaningful changes in environmental governance. They furthermore argued that, since $3 R Q$ is part of West Virginia State's designated Water Research Institute, they were not in a position to use data beyond the purposes of research.

\section{Renegotiating the Terms of Knowledge Infrastructures}

Growing discord between how grassroots groups and research partners envisioned the purpose of the $3 \mathrm{RQ}$ threatened to unravel the KI. Numerous mini-grantees began to question their commitments to a KI that did not help them address their immediate environmental concerns. Similar complaints came from monitoring groups outside $3 R Q$ that had been pressured to contribute data to the QUEST Data Management Tool.

These complaints had an interesting effect. By 2015, Colcom and WVWRI had invested more than $\$ 1.6$ million to establish $3 R Q$ as a regional hub for water monitoring research. 3RQ's leaders and funders took note of growing dissatisfaction and began to reevaluate the effectiveness of the infrastructure KI they had built. 3RQ modified the QUEST Data Tool tiers to indicate which protocols were used when collecting data, rather than what kind of organization did the collecting. Tier 3 now denotes data verified by an analytical lab, Tier 2 includes data collected with protocols such as ALLARM's, and Tier 1 is for data collected by individuals without known quality controls. Breaking the symbolic link between data's source and data's legitimacy was significant for nonprofessional groups who felt marginalized by 3RQ's expertcentric power structure.

A second major change came in June of 2015, when Colcom awarded 3RQ a fourth grant for $\$ 350,000$. These funds established a program called REACH (Research Enhancing Awareness via Community Hydrology) and brought on four outreach coordinators to serve as links between 3RQ's researcher partners and local watershed groups (West Virginia University, 2015). REACH and changes to the tiered data structure represented a shift towards greater capacity for empowerment within 3RQ's KI.

\section{Discussion}

On their surfaces, the knowledge infrastructures designed by water monitoring networks in the Marcellus Shale are surprisingly similar-they 
propagated standardizes protocols, provided access to testing equipment, offered training to new members, developed a means to work with data, and created pathways to partner with scientific experts. These "internetworks of people, artifacts, and institutions" (Edwards et al., 2013: 23) addressed the needs of NY Water Sentinels' and 3RQ's affiliates and were constructed for similar reasons. People believed that investing in KIs would bring together diverse resources and knowledge to address shale oil and gas extraction's risks to watersheds. However, the participation models adopted in these infrastructures significantly impacted how stakeholders retained control in decision-making processes.

These two studies shed light on the nature of power sharing in Kls. In the case of the NY Water Sentinels, member groups enjoyed a high degree of autonomy to address new environmental pollution concerns as they arose. Their grassroots governing system afforded mechanisms for individuals to influence daily operations and ask new questions with their science. By comparison, local watershed organizations that aligned with $3 R Q$ gained access to professional-grade resources and mini-grants brought forth new equipment and staff. However, 3RQ's partnership structure reinforced the authority of watershed experts while claiming to do co-designed research. Minigrantees were able to hook into a sophisticated $\mathrm{Kl}$, but were immediately marginalized by the constraining priorities of 3RQ's research partners.

The two studies also demonstrate that the inner workings of Kls change over time when some stakeholders begin to assert greater influence. This was seen at two distinct points in the NY Water Sentinels' development. One occurred when a number of individuals inserted new objectives into their daily monitoring activities. The other turning point coincided with the NY Water Sentinels becoming a sub-program of the Sierra Club. For $3 R Q$, power shifts occurred for different reasons. Despite being part of one of the most resource-rich water monitoring networks in the Marcellus Shale, many of 3RQ's member organizations had little control in directing 3RQ's KI. Dissatisfaction became visible when members voiced concern about the ways their data was being managed and how research partners responded to their advocacy needs. Rather than breaking down, 3RQ's $\mathrm{KI}$ was transformed by tactics like choosing not to share data. The REACH initiative and changes to QUEST's tier structure represented a ceding of power; they illustrate how marginalized groups can alter Kls through various forms of resistance.

Finally, the NY Water Sentinels and $3 R Q$ provide insights into the nature of empowerment in Kls. Corbett and Keller (2005a) offer a framework to assess empowerment and empowerment capacity at different scales: at the level of the individual and at the level of community. When brought to the study of Kls, this framework exposes some of the tradeoffs that occur when building Kls. Individuals who viewed landfill waste as a major threat were empowered by the NY Water Sentinels governing system, but one could also argue that the durability of their KI suffered due to internal frictions and competing objectives. Aligning with the Sierra Club may have saved the Kl, but the constraints that come with this new partnership could, in the future, disempower the organizing capacities of affiliated monitoring groups. These are significant findings that deserve additional research into how Kls can effectively bridge dispersed research communities while maximizing capacity for collective empowerment.

Whether or not REACH will empower grassroots groups who invested in 3RQ's KI remains to be seen. It is likely that some mini-grantees will find some degree of empowerment by working with 3RQ's new community outreach coordinators; for instance, by having more resources to interpret their data. Generating long-term empowerment capacity to deal with environmental impacts is less certain. Academic researchers would have to share resources and utilize local knowledge in their work, thus yielding entrenched power to the voices and science of nonprofessionals.

\section{Conclusion}

Susan Leigh Star (1999: 382) once agued that "because infrastructure is big, layered, and complex, and because it means different things locally, it is never changed from above. Changes take time and negotiation, and adjustment with other aspects of the systems are involved. Nobody is 
really in charge of infrastructure." The arguments offered in this paper complement Star's sensibility. The Marcellus Shale water monitoring community emerged in order to deal with complex environmental and public health risks introduced by shale oil and gas extraction. Those who came together to build Kls for water monitoring research brought with them a wide spectrum of resources, expertise, and objectives. In studying this community, I have found it important to not only evaluate how KIs emerge, but also how power plays out in their emergence. What one finds is that KIs, even when seemingly stable in their leadership and intended purpose, are indeed dynamic spaces where relationships of power are rarely settled.

Subsequently, one must also give consideration to how Kls empower and disempower people in their daily lives. Many other regions in U.S. and abroad are paying close attention to public responses to oil and gas extraction's health and environmental threats in the Marcellus Shale. States with recently discovered shale formations, such as Florida, are setting regulatory frameworks that will determine how they assess the risks of hydraulic fracturing. Other states are shutting down channels of public participation and regulatory transparency. Wyoming recently criminalized citizen data collection on "open land"_-land outside the jurisdiction of established cities and town (Pidot, 2015). In North Carolina, legislators outlawed disclosures of hydraulic fracturing chemicals in order to attract energy companies (Rosenberg, 2014).

Concerned citizens in these at-risk geographies are evaluating effective strategies for political resistance. Decisions made within the Marcellus Shale advocacy community will almost certainly propagate there and elsewhere. It is therefore critical to understand how these strategies-civil society science being one-struggle and succeed in overcoming barriers of public participation and influence. Knowledge infrastructures that emerge in these spaces can generate and curate new knowledge, is evident in many previous studies, but they can also assist marginalized communities to build capacity and mobilize resources when empowerment is a set intention in their design. 


\section{Note}

1 The current version of the QUEST Data Management Tool can be found at http://3riversquest.org/ (Last accessed July 27, 2015).

\section{Acknowledgements}

This research was supported in part by the National Science Foundation, under Award \#1331080 and Award $\# 1126235$. Any opinions, findings, and conclusions or recommendations expressed in this material are those of the author and do not necessarily reflect the views of the National Science Foundation.

\section{References}

Bijker WE, Hughes T \& Pinch T (eds) (1987) The Social Construction of Technological Systems: New Directions in the Sociology and History of Technology. Cambridge, MA: MIT Press.

Borgman CL, Wallis JC \& Mayernik MS (2012) Who's Got the Data? Interdependencies in Science and Technology Collaborations. Computer Supported Cooperative Work (CSCW) 21(6): 485-523.

Bowker GC, Baker KS, Millerand F \& Ribes D (2010) Toward information infrastructure studies: Ways of knowing in a networked environment. In: Hunsinger J, Klastrup L \& Allen MM (eds) International Handbook of Internet Research. London, UK: Springer, 97-117.

Bowker GC \& Star SL (1999) Sorting Things Out: Classification and Its Consequences. Cambridge, MA: MIT Press.

Corbett, JM \& Keller CP (2005a) An Analytical Framework to Examine Empowerment Associated with Participatory Geographic Information Systems (PGIS). Cartographica: The International Journal for Geographic Information and Geovisualization 40(4): 91-102.

Corbett, JM \& Keller CP (2005b) Empowerment and Participatory Geographic Information and Multimedia Systems: Observations from Two Communities in Indonesia. Information Technologies and International Development 2(2): 25-44.

Corburn J (2005) Street Science: Community Knowledge and Environmental Health Justice. Cambridge, MA: MIT Press.

Donlin P (2010) DEP investigating frack fluid spill near Hughesville. Lock Haven Express, 23 November. Available at: http://www.lockhaven.com/page/content.detail/id/527442.html (accessed 14.4.2015).

Donohue DM (2015) DEC extends Hyland landfill comment period. Olean Times Herald, 19 January. Available at: http://www.oleantimesherald.com/news/article_81aff232-a028-11e4-82a7-877ba728f765.html (accessed 27.7.2015).

Edwards PN, Bowker GC, Jackson SJ \& Williams R (2009) Introduction: An agenda for infrastructure studies. Journal of the Association of Information Systems 10(5): 364 - 374.

Edwards PN, Jackson SJ, Chalmers MK, Bowker GC, Borgman CL, Ribes D, Burton M \& Calvert S (2013) Knowledge Infrastructures: Intellectual Frameworks and Research Challenges. Ann Arbor, MI: Deep Blue.

Edwards PN, Mayernik MS, Batcheller AL, Bowker GC \& Borgman CL (2011) Science Friction: Data, metadata, and collaboration. Social Studies of Science 41(5): 667-690.

Entrekin S, Evans-White M, Johnson B \& Hagenbuch E (2011) Rapid Expansion of Natural Gas Development Poses a Threat to Surface Waters. Frontiers in Ecology and the Environment 9(9): 503-511.

Fischer F (2000) Citizens, Experts, and the Environment: the Politics of Local Knowledge. Durham, NC: Duke University Press. 
Gouveia C, Fonseca A, Câmara A \& Ferreira F (2004) Promoting the use of environmental data collected by concerned citizens through information and communication technologies. Journal of Environmental Management 71(2): 135-54.

Hardman E (2014) Is there leachate on tap? A report from Bath, NY. Rochester Indymedia, 22 September. Available at: http://rochester.indymedia.org/node/104041 (accessed 22.4.2015).

Hughes T (1987) The evolution of Large Technological Systems. In: Bijker WE, Hughes T \& Pinch T (eds) The social construction of technological systems: New directions in the sociology and history of technology. Cambridge, MA: MIT Press, 51-82.

Irwin A (2001) Constructing the Scientific Citizen: Science and Democracy in the Biosciences. Public Understanding of Science 10(1): 1-18.

Jalbert K \& Kinchy AJ (2015) Sense and Influence: Environmental Monitoring Tools and the Power of Citizen Science. Journal of Environmental Policy \& Planning 2: 0-19.

Jalbert K, Kinchy AJ \& Perry SL (2014) Civil Society Research and Marcellus Shale Natural Gas Development: Results of a Survey of Volunteer Water Monitoring Organizations. Journal of Environmental Studies and Sciences 4(1): 78-86.

Kinchy AJ \& Perry SL (2012) Can Volunteers Pick Up the Slack? Efforts to Remedy Knowledge Gaps About the Watershed Impacts of Marcellus Shale Gas Development. Duke Environmental Law \& Policy Forum 22(2): 303-339.

Lave R (2012) Neoliberalism and the Production of Environmental Knowledge. Environment and Society: Advances in Research 3(1): 19-38.

Llewellyn GT, Dorman F, Westland JL, Yoxtheimer D, Grieve P, Sowers T, Humston-Fulmer E \& Brantley SL (2015) Evaluating a groundwater supply contamination incident attributed to Marcellus Shale gas development. Proceedings of the National Academy of Sciences 112(20): 201420279.

Malone S, Kelso M, Auch T, Edelstein K, Ferrar K \& Jalbert K (2015) Data inconsistencies from states with unconventional oil and gas activity. Journal of Environmental Health and Science 50(5): 37-41.

Mantius P (2013) New York Imports Pennsylvania's Radioactive Fracking Waste Despite Falsified Water Tests. DC Bureau Natural Resources News Service, 14 August. Available at: http://www.dcbureau. org/201308148881/natural-resources-news-service/new-york-imports-pennsylvanias-radioactivefracking-waste-despite-falsified-water-tests.html (accessed 27.7.2015).

Moore K (2006) Powered by the People: scientific authority in participatory science. In: Frickel S \& Moore K (eds) The New Political Sociology of Science: Institutions, Networks, and Power. Madison, WI: University of Wisconsin Press, 299-323.

Moran E (2015) License to Dump: Despite Ban, New York Permits Pennsylvania to Dump Radioactive Fracking Waste Inside Our Borders. Environmental Advocates of New York. Available at: http://www.eany.org/ our-work/reports/license-dump-february-2015 (accessed 27.7.2015).

Morello-Frosch R, Pastor M, Sadd JL, Porras C \& Prichard M (2005) Citizens, science, and data judo: Leveraging secondary data analysis to build a community-academic collaborative for environmental justice in Southern California. In: Schulz AJ \& Parker EA (eds) Methods in community-based participatory research for health. San Francisco, CA: Jossey-Bass, 371-392.

NYS Department of Environmental Conservation (2006) Regulations Part 371: Identification and Listing Of Hazardous Wastes. Available at: http://www.dec.ny.gov/regs/14897.html (accessed 4.22.2015).

O'Rourke D \& Macey GP (2003) Community environmental policing: Assessing new strategies of public participation in environmental regulation. Journal of Policy Analysis and Management 22(3): 383-414. 
Ottinger G (2009) Buckets of Resistance: Standards and the Effectiveness of Citizen Science. Science, Technology \& Human Values 35(2): 244-270. http://doi.org/10.1177/0162243909337121

Overdevest C \& Mayer B (2008) Harnessing the Power of Information through Community Monitoring: Insights from Social Science. Texas Law Review 86(1493): 1493-1526.

Pfeffer, Max J, and Linda P. Wagenet (2007) Volunteer environmental monitoring, knowledge creation and citizen-scientist interaction. The SAGE handbook of environment and society. Sage, London, 235-250.

Pidot J (2015). Wyoming law against data collection: Protecting ranchers by ignoring the environment. Slate. com, 11 May. Available at: http://www.slate.com/articles/health_and_science/science/2015/05/wyoming_ law_against_data_collection_protecting_ranchers_by_ignoring_the.html (accessed 12.2.2016).

Pinch T \& Bijker WE (1987) The Social Construction of Facts and Artifacts: Or How the Sociology of Science and the Sociology of Technology Might Benefit Each Other. In: Bijker W, Hughes T \& Pinch T (eds) The Social Construction of Technological Systems. Cambridge, MA: The MIT Press.

Puko T (2013) Radioactive fracking debris triggers worries at dump sites. Pittsburgh TribuneReview, 11 May. Available at: http://triblive.com/business/headlines/3945499-74/gas-radiationradioactivity\#axzz3aX2cieYp (accessed 27.7.2015).

Ribes D \& Finholt TA (2009) The Long Now of Technology Infrastructure: Articulating Tensions in Development. Journal of the Association for Information Systems 10(5): 375-398.

Rosenberg M (2014) North Carolina Senate outlaws disclosure of fracking fluid secrets. Thomson Reuters, 22 May. Available at:http://www.reuters.com/article/us-usa-fracking-secrets-idUSBREA4LOYC20140522 (accessed 12.2.2016).

Savan B, Morgan AJ \& Gore C (2003) Volunteer Environmental Monitoring and the Role of the Universities: The Case of Citizens' Environment Watch. Environmental Management 31(5): 561-568.

Shirk JL, Ballard HL, Wilderman CC, Phillips T, Wiggins A, Jordan R, McCallie E, Minarchek M, Lewenstein BV, Krasny ME \& Bonney R (2012) Public Participation in Scientific Research: a Framework for Deliberate Design. Ecology and Society 17(2): 29.

Soraghan M (2011) Frack Study's Safety Findings Exaggerated, Bush EPA Official Says. The New York Times, 20 May. Available at: http://www.nytimes.com/gwire/2011/05/20/20greenwire-frack-studys-safety-findingsexaggerated-bush-65374.html (accessed 14.4.2015).

Star SL (1999) The Ethnography of Infrastructure. American Behavioral Scientist 43(3):377-391.

Star SL \& Ruhleder K (1996) Steps Toward an Ecology of Infrastructure: Design and Access for Large Information Spaces. Information Systems Research 7(1): 111-134.

US Energy Information Agency (1993) Drilling Sideways - A Review of Horizontal Well Technology and Its Domestic Application, DOE/EIA-TR-0565. Available at: http://www.eia.gov/pub/oil_gas/natural_gas/ analysis_publications/drilling_sideways_well_technology/pdf/tr0565.pdf (accessed 28.7.2015).

US Energy Information Agency (2013) Technically Recoverable Shale Oil and Shale Gas Resources: An Assessment of 137 Shale Formations in 41 Countries Outside the United States. Available at: https://www.eia.gov/ analysis/studies/worldshalegas/archive/2013/pdf/fullreport_2013.pdf (accessed 10.2.2016).

Wagenet LP \& Pfeffer MJ (2007) Organizing Citizen Engagement for Democratic Environmental Planning. Society \& Natural Resources, 20(9): 801-813.

West Virginia University (2013) Regional water quality monitoring program receives $\$ 508,000$ grant; allows researchers to identify long-term trends. WVU Today, 24 September. Available at: http://wvutoday. wvu.edu/n/2013/09/24/regional-water-quality-monitoring-program-receives-508-000-grant-allowsresearchers-to-identify-long-term-trends (accessed 22.4.2015). 
West Virginia University (2015) $\$ 350,000$ grant expands WVU water quality monitoring of three rivers. WVU Today, 3 June. Available at: http://wvutoday.wvu.edu/n/2015/06/03/350-000-grant-expands-wvu-waterquality-monitoring-of-three-rivers-community-outreach-funded-for-targeting-trouble-spots (accessed 27.7.2015). 